\title{
EDUCATION
}

\section{What influences intention to become a postgraduate trainer?}

\author{
D. Bonetti, ${ }_{1}$ J. Ross, ${ }_{1}^{2}$ S. Stewart ${ }^{3}$ and J. Clarkson ${ }^{4}$
}

\begin{abstract}
Objective Only a small proportion of eligible dentists become dental vocational trainers. The aim of this study was to apply Social Cognitive Theory to further an understanding of beliefs underpinning intention to become a dental vocational trainer. Subjects Primary care dentists.

Design A self-administered questionnaire was distributed at all continuing professional development courses during November 2004 regardless of course enrolment numbers, content or duration.

Outcome measure Intention to train.

Predictive measures Attitude toward being a trainer, attitude toward attending the trainer course, and confidence in ability to train (training self-efficacy).

Results Of the 316 respondents, 47\% intended never to train. Training self-efficacy accounted for the majority of variance in intention to train (15\%, step 1) with attitude to training accounting for a further 4\% (step 2) (Hosmer and Lemeshow test: Chi-square $=7.36$, $d f=8, p=0.498 ; 95 \% \mathrm{Cl}$ for $\operatorname{EXP}(b)$ : training self-efficacy $=1.38-2.06$, attitude $=1.17-2.08)$. Attitude to the trainer course did not enter the regression model. The most influential belief relating to intention to train was confidence in teaching, and for intention never to train was evaluating a trainee's skills. Both intenders and non-intenders believed training and attending training courses would be time-consuming and financially costly, suggesting these are not primary factors in making the decision to become a trainer.

Conclusions Using a psychological model provided a starting point for understanding intention to become a vocational trainer and a rationale for the format of future interventions. Results suggest intention to train may be influenced by targeting dentists' confidence in teaching and performing evaluative aspects of training.
\end{abstract}

\section{INTRODUCTION}

All newly qualified dentists wishing to obtain an NHS list number are required to undertake dental vocational training. This involves a vocational dental practitioner (VDP) spending a year under the tutelage of an experienced dentist who oversees their preparation for independent general dental practice. There is evidence that this postgraduate training year successfully enhances skills and

\footnotetext{
${ }^{1 *}$ Research Fellow, Dental Health Services Research Unit, University of Dundee, Mackenzie Building, Kirsty Semple Way, Dundee, DD2 4BF; 2,3Training Development and Support Unit, NHS Education for Scotland, The Lister, 11 Hill Square, Edinburgh, EH8 9DR: ${ }^{4}$ Director, Effective Dental Practice Programme/Honorary Consultant in Paediatric Dentistry, Dental Health Services Research Unit, University of Dundee, Mackenzie Building, Kirsty Semple Way, Dundee, DD2 4BF

Correspondence to: Dr Debbie Bonetti

Email:d.bonetti@chs.dundee.ac.uk
}

\section{Refereed Paper}

Accepted 24 April 2007

DOI: 10.1038/bdj.2007.780

${ }^{\circledR}$ British Dental Journal 2007; 203 (Suppl): 31-35 confidence, and that it can be a means of raising and maintaining standards in the general dental service. ${ }^{1-5}$ Building on this success, the current move across the UK is toward mandatory formal assessment throughout this vocational training year. There is also debate about increasing the length of the vocational training period.

The issue that has arisen is not about the effectiveness of vocational training per se - but whether there are going to be enough dentists who are willing to become vocational trainers to meet future demand. If dental graduates cannot find a place with a trainer, then they cannot practice as NHS dentists. This is of particular relevance in the current climate of uncertainty and recrimination relating to lack of access to NHS dentists and waiting times.

In order to be eligible to become a vocational trainer in Scotland, a dentist has to have 75 hours of verifiable CPD over five years, NHS earnings of at least 20\% of TAGI (currently £24,340) and attend a vocational trainer course involving one three-day, two two-day and three one-day modules (70 hours of verifiable CPD). Vocational training advisers from NHS National Education for Scotland (NES) estimate that only $15 \%$ of dentists in Scotland who may be eligible to become vocational trainers are training VDPs (based on current number of trainers and NHS list numbers). The trainer recruitment rate over the last three years has been insufficient to both cover attrition and simultaneously increase the number of trainers to the level that will be required for the increased graduate numbers anticipated in the near future.

Already in place are substantial monetary incentives. A vocational trainer in Scotland receives a training allowance as well as a training grant. They have access to practice improvement grants. Their practice benefits from the addition of an extra pair of hands as well as the trainee's gross earnings. 


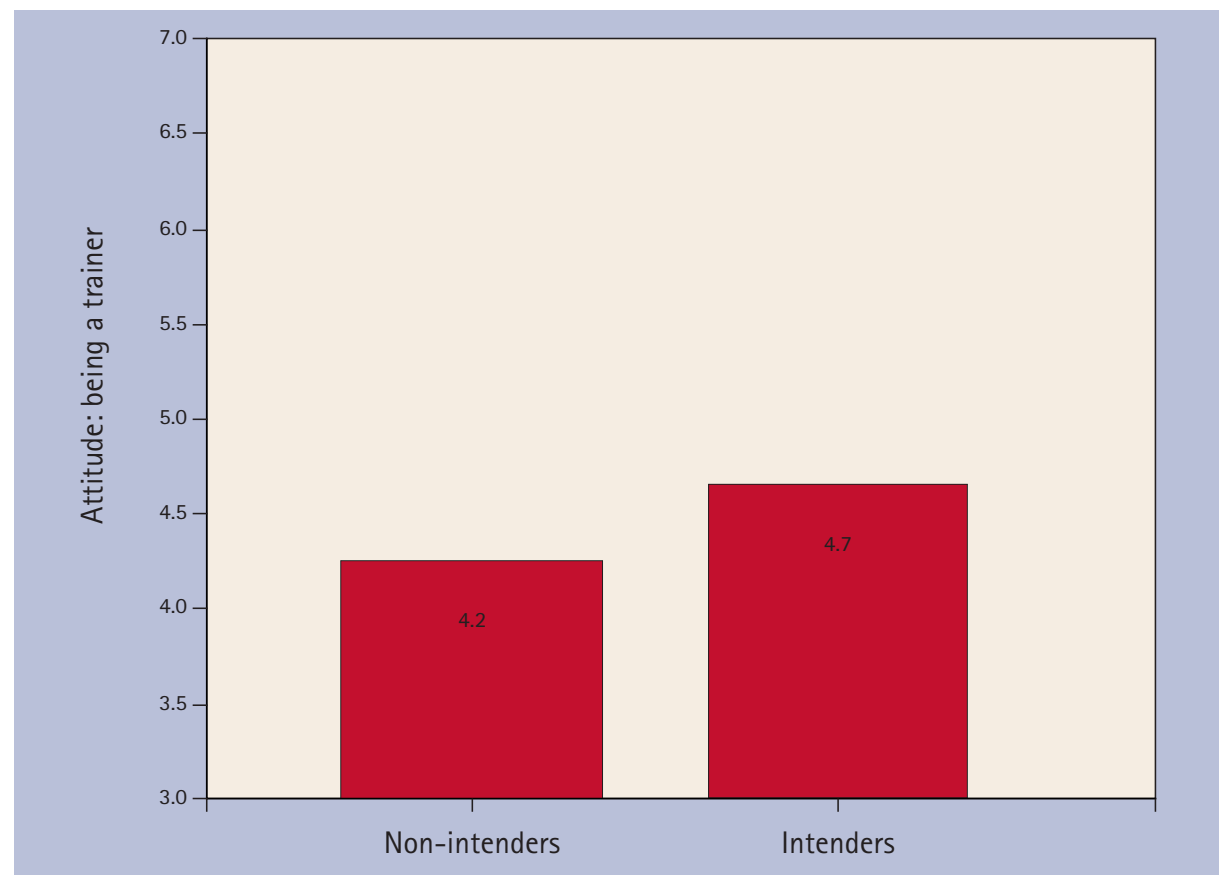

Fig. 1 Comparing intenders and non-intenders: attitude toward being a trainer (mean scores)

Currently there is no knowledge about what influences the decision to become a vocational trainer. The aim of this study was to further an understanding of the beliefs underpinning intention to become a vocational trainer in Scotland. The overall aim is to inform the design of future recruitment strategies.

Psychology theories have been developed to understand, predict and influence behaviour and have already proved useful when applied to the behaviour of patients and the general public. ${ }^{6,7}$ Recent investigations have explored the possibility of applying these models to understanding clinicians' behaviour and to the design of interventions to influence clinicians' decision-making. ${ }^{8-10}$

One such model is Social Cognitive Theory. ${ }^{11}$ This theory proposes that two main sets of beliefs about performing a behaviour influence whether or not we actually perform the behaviour. The first set of beliefs is about what we expect to be the consequences of performing a behaviour (outcome expectancies). The theory proposes that we are more likely to perform a behaviour if we have an overall positive attitude about it, that is, if we expect that the positive consequences of doing something outweigh the negative consequences of doing it. The second set of beliefs is about whether we expect we can perform the behaviour (self-efficacy expectancies). We are more likely to perform a behaviour if we have confidence in our ability to do it. Outcome and selfefficacy beliefs influence whether we are likely to perform a behaviour by influencing motivational elements, such as our mood, how we think about ourselves and our persistence in the face of obstacles.

The advantage of using a theoretical framework is that, in addition to suggesting variables likely to influence behaviour, a methodology is also provided for influencing these variables. The rationale of this study was that this theoretical framework could be applied to understanding beliefs that underpin motivation (intention) to become a vocational trainer. This would make it possible to design an informed intervention, that is, a recruitment strategy, with the greatest likelihood of success in terms of encouraging dentists to become vocational trainers.

\section{METHODS}

This study was designed as a self-administered questionnaire survey. Participants were dentists working in primary care attending any professional development course during November 2004. The questionnaire was distributed by regional office course convenors at the beginning of every CPD course, irrespective of course enrolment numbers, content or duration. The course convenors simply introduced the questionnaire as part of a dental audit study and requested dentists to complete the questionnaires in their own time, after which they should place them in a designated box by the end of each course.

The main outcome was intention to become a trainer. The questionnaire item was: 'Do you intend ever to become a vocational trainer?' The response options were never / in next year / next 2-3 years / next 4-5 years / don't know. Since the primary interest of the study investigators was to understand beliefs differentiating dentists who had definitely decided never to become a vocational trainer from dentists who were open to the possibility of becoming trainers, the main analysis grouped responses to examine this as a dichotomous variable: non-intenders (never) and intenders (in next year / next 2-3 years / next 4-5 years / don't know).

The predictive measures were attitude toward being a trainer, attitude toward attending the trainer course and training self efficacy (confidence in ability to train). The questionnaire items were informed by consultations with ten stakeholders: NES trainer course convenors, clinicians, clinical researchers and a health psychologist. The measures were then designed using theory measurement protocols. ${ }^{11,12}$ Table 1 provides a summary of the measures used in this study.

Data were analysed using SPSSPC. ${ }^{13}$ Data from 10\% of returned questionnaires were double-entered and descriptive statistics were examined for accuracy of data entry. Data were examined for outliers using $\mathrm{z}$ scores $>3.29(\mathrm{p}=0.001)$. Measures were examined for their approximation to a normal distribution using skewness and kurtosis statistics greater than \pm 1 . Differences between dentists who intend to become vocational trainers (intenders) and dentists who do not intend to become vocational trainers (non-intenders) were examined using descriptive statistics, Chi-square and t-test analyses. The relationships between predictive measures and intention to train were examined using logistic regression analyses.

\section{RESULTS}

Data were found to be within normal parameters and no outliers were identified. 
There were 316 dentists who returned questionnaires out of a possible 800 (40\% response rate). The demographics of participants were:

- 59\% were male

- $52 \%$ were principals in their practice, 38\% were associates, 10\% were salaried/assistants, 24\% had qualified within the last ten years

- 75\% had never been vocational trainers, $11 \%$ had been vocational trainers within the last two years

- 57\% cited their practice as town, 32\% as inner city, $8 \%$ as village, and $2 \%$ as remote

- 36\% cited their practice was located in South East Scotland, 34\% in West Scotland, 16\% in North East Scotland, $13 \%$ in East Scotland, and 1\% in North Scotland.

Forty-eight percent of respondents said they did intend to become a trainer, 47\% said they intend never to become a trainer at this point in time and 5\% said they did not know if they would become trainers. of the dentists who intended to become trainers, 39\% said they would consider becoming a trainer in the next 12 months, $25 \%$ would consider becoming a trainer in the next two to three years and 36\% in the next four to five years. Seventeen participants did not complete the intention to train item (outcome measure) and so were not included in the following analyses.

There were no significant differences ( $p$ $>0.05$ ) in intention to become a trainer by region, gender, practice location, or number of days worked per week. However, compared with dentists who intend never to become a trainer, dentists who intend to become trainers have significantly higher training self-efficacy (ie have more confidence in their ability to train), have a significantly more positive attitude toward training and a significantly more positive attitude toward the trainer course (Figs 1-3).

Logistic regression analyses revealed that training self-efficacy accounted for the majority of the variance explained in intention to become a trainer (15\%, step 1) with attitude to training accounting for a further 4\% of the variance explained (step 2) (Hosmer and Lemeshow test: Chi-square $=7.36, \mathrm{df}=8, \mathrm{p}=0.498 ; 95 \% \mathrm{CI}$ for $\operatorname{EXP}(\mathrm{b})$ :

\begin{tabular}{|c|c|c|c|c|}
\hline Measures & Items & $\begin{array}{l}\text { Non- } \\
\text { intenders } \\
(n=140)\end{array}$ & $\begin{array}{l}\text { Intenders } \\
(n=159)\end{array}$ & $p$ \\
\hline $\begin{array}{l}\text { Attitude toward } \\
\text { being a trainer }\end{array}$ & $\begin{array}{l}\text { Training a VDP would be: } \\
\text { Stimulating } \\
\text { Time-consuming } \\
\text { Financially costly ( } € \text { ) } \\
\text { Developing for the practice } \\
\text { Developing for my clinical skills } \\
\text { Financially beneficial for } \\
\text { practice income ( } € \text { ) } \\
\text { Advantageous for the dental } \\
\text { service in my area } \\
\text { Detrimental to the practice } \\
\text { Upsetting for the patients } \\
\text { Interfering with my personal life } \\
\text { Detract from my clinical role }\end{array}$ & $\begin{array}{l}4.78(1.54) \\
2.78(1.53) \\
3.78(1.46) \\
4.47(1.43) \\
4.45(1.38) \\
3.88(1.27) \\
4.74(1.60) \\
4.76(1.41) \\
4.38(1.43) \\
4.35(1.65) \\
4.21(1.66)\end{array}$ & $\begin{array}{l}5.37(1.62) \\
3.10(1.65) \\
3.72(1.47) \\
5.15(1.55) \\
5.11(1.53) \\
4.24(1.34) \\
5.18(1.47) \\
5.27(1.53) \\
4.72(1.52) \\
4.68(1.61) \\
4.62(1.58)\end{array}$ & $\begin{array}{l}* * * \\
\mathrm{~ns} \\
\mathrm{~ns} \\
* * * \\
* * * \\
* \\
* \\
* \\
* \\
* \\
\text { ns } \\
*\end{array}$ \\
\hline $\begin{array}{l}\text { Attitude toward attending } \\
\text { the trainer course }\end{array}$ & $\begin{array}{l}\text { Attending trainer training } \\
\text { would be: } \\
\text { Stimulating } \\
\text { Time-consuming } \\
\text { Financially costly (f) } \\
\text { Develop my non-clinical skills }\end{array}$ & $\begin{array}{l}5.22(1.34) \\
2.82(1.38) \\
3.52(1.32) \\
5.16(1.36)\end{array}$ & $\begin{array}{l}5.63(1.36) \\
2.98(1.55) \\
3.56(1.45) \\
5.51(1.43)\end{array}$ & $\begin{array}{l}{ }^{* *} \\
\text { ns } \\
\text { ns } \\
*\end{array}$ \\
\hline $\begin{array}{l}\text { Self-efficacy: } \\
\text { confidence in ability } \\
\text { to train }\end{array}$ & $\begin{array}{l}\text { How confident are you that } \\
\text { you can: } \\
\text { Understand the application } \\
\text { process } \\
\text { Prepare the practice for a trainee } \\
\text { Make time to train } \\
\text { Carry out audit } \\
\text { Appraise your trainee } \\
\text { Keep up to date with } \\
\text { evidence-based practice } \\
\text { Design tutorials } \\
\text { Deliver tutorials } \\
\text { Teach clinical skills } \\
\text { Develop opportunistic training } \\
\text { for your trainee } \\
\text { Evaluate a trainee's skills } \\
\text { Give a trainee feedback }\end{array}$ & $\begin{array}{l}3.46(1.99) \\
3.38(1.99) \\
2.84(1.78) \\
4.54(1.81) \\
3.89(1.75) \\
4.65(1.47) \\
3.70(1.62) \\
3.74(1.69) \\
4.46(1.50) \\
3.67(1.54) \\
4.18(1.61) \\
4.34(1.56)\end{array}$ & $\begin{array}{l}4.45(1.93) \\
4.94(1.83) \\
4.79(1.81) \\
5.06(1.62) \\
4.82(1.52) \\
4.94(1.33) \\
4.52(1.54) \\
4.65(1.55) \\
5.19(1.24) \\
4.66(1.42) \\
4.77(1.35) \\
4.89(1.33)\end{array}$ & $\begin{array}{l}{ }^{* * *} \\
{ }^{* *} \\
{ }^{* * *} \\
{ }^{* *} \\
{ }^{* * *} \\
\text { ns } \\
{ }^{* * *} \\
{ }^{* *} \\
{ }^{* * *} \\
\end{array}$ \\
\hline
\end{tabular}

training self-efficacy $=1.38-2.06$, attitude $=1.17-2.08$ ). Attitude to the trainer course did not enter the final model.

The analyses were repeated, including only dentists who had never trained before ( $n=236)$. Forty-four percent intended to become a trainer, 54\% said they intend never to become a trainer at this point in time and 2\% did not answer. The results for this subgroup analyses were unchanged, in that the dominant influence behind formulating an intention to train in dentists who have never trained before was also training self-efficacy, which accounted for the majority of the variance explaining intention to become a trainer (9\%, Hosmer and Lemeshow test: Chisquare $=2.72, \mathrm{df}=8, \mathrm{p}=0.951$ ).

Differences between intenders and non-intenders were then analysed item by item (Table 1). Three items in the 11item attitude to training measure showed 


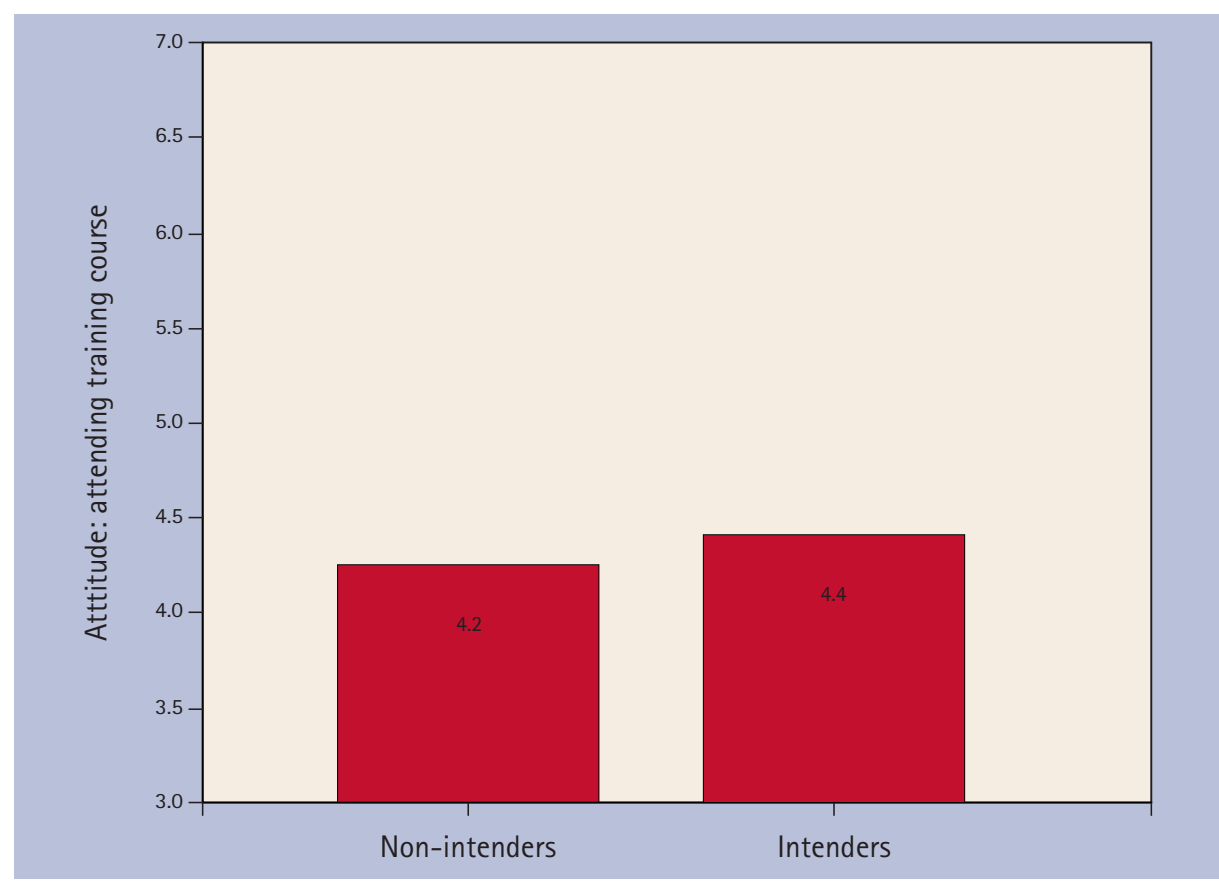

Fig. 2 Comparing intenders and non-intenders: attitude toward attending a trainer course (mean scores)

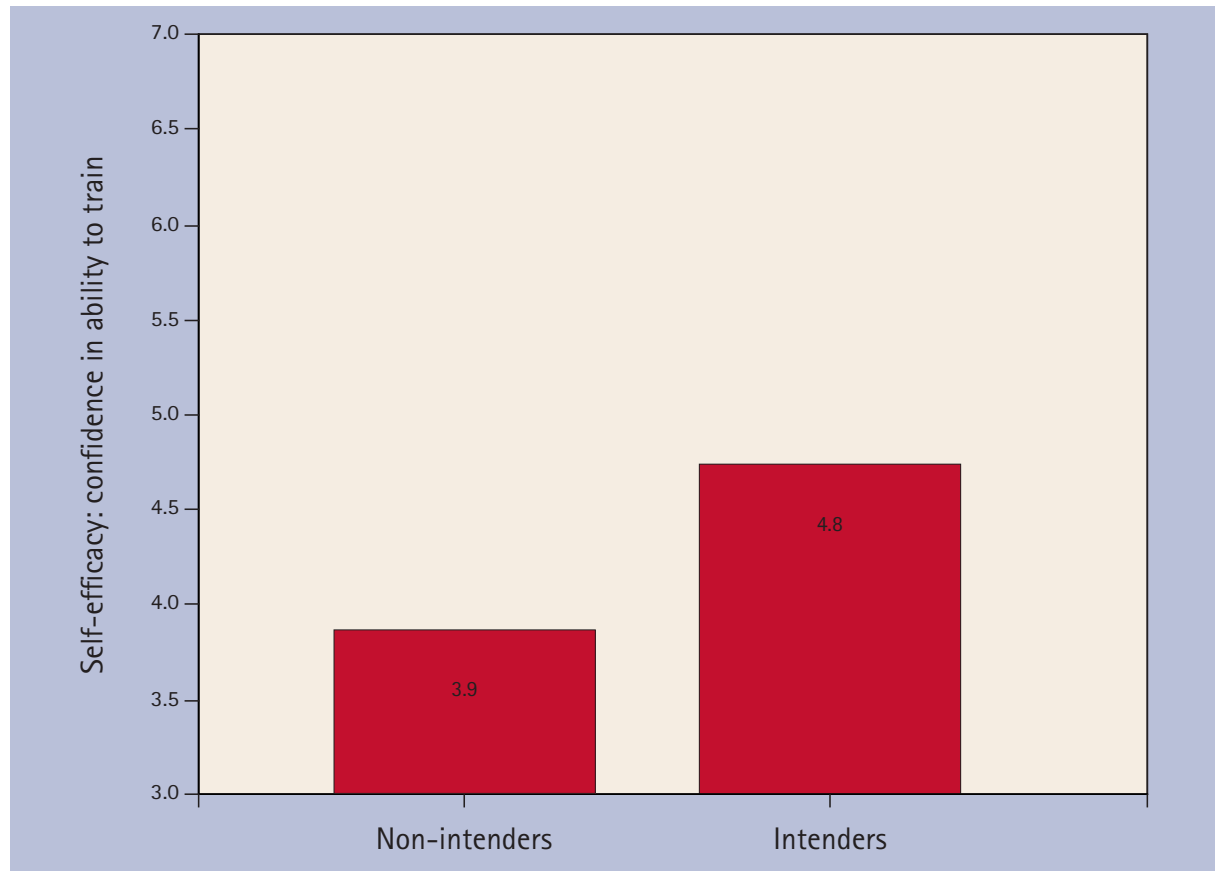

Fig. 3 Comparing intenders and non-intenders: training self-efficacy (confidence in ability to train)

no significant difference in intention to train. Despite an overall positive attitude to training a VT (mean >3.5), both intenders and non-intenders believe that training a VDP would be time-consuming, would interfere with their personal life and would be financially costly. The items which appear to be most influential for this attitude measure - if they were dropped, the measure of internal reliability (Cronbach alpha $=0.80$ ) decreased - related to training detracting from the clinical role (intenders) and training being detrimental to the practice (non-intenders).

Two items of the four-item attitude to trainer course measure showed no significant difference in intention to train. Both intenders and non-intenders believe that attending the training course would be time-consuming and financially costly (Table 1). However, dentists who intended to become trainers were significantly more likely to believe the trainer course would be stimulating $(\mathrm{t}(1,297)=2.60, \mathrm{p}$ $<0.01)$ and would develop their non-clinical skills $(\mathrm{t}(1,297)=2.11, \mathrm{p}<0.05)$.

Only one item in the 12-item training self-efficacy measure showed no significant difference between the intention groups. Both intenders and non-intenders are confident they can keep up to date with evidence-based practice. The items which appeared to be most influential related to designing and delivering tutorials (intenders) and confidence in evaluating a trainee's skills (non-intenders).

\section{DISCUSSION}

These results provide evidence that dentists in this study who intend to become vocational trainers and dentists who intend never to become a vocational trainer, both recognise that training would be time-consuming, would interfere with their personal life and would be financially costly. Since both groups equally acknowledge these barriers, this strongly supports the idea that cost is not the motivating issue in terms of developing an intention to become a vocational trainer. Instead, the results strongly suggest that the main driver of intention to train was dentists' confidence in their ability to train (training self-efficacy).

The results of the item analyses further suggest that intenders and non-intenders have different concerns driving their confidence in their ability to train. Dentists who intend to become a vocational trainer appear to be mainly concerned about the teaching aspects of training (designing and delivering tutorials). Dentists who intend never to become a vocational trainer appear to be most concerned about performing the evaluative element of training, as in critiquing the skills of trainees.

The variables that Social Cognitive Theory propose as predictive of behaviour did distinguish between intenders and non-intenders. This suggests that this psychological model can be applied to the decision to become a vocational trainer and so may be used as a framework to design an informed recruitment intervention encouraging dentists to become vocational trainers. The model proposes that self-efficacy beliefs can be 
influenced by verbal persuasion, vicarious experience (watching someone else perform the behaviour), performing the behaviour and physiological state. An intervention based on this model would therefore use these elements to influence training self-efficacy. Given that all dentists in Scotland are currently sent a pamphlet about the vocational trainer course, one possible intervention would be an accompanying letter which included statements about the positive aspects of being a vocational training from existing trainers and course convenors (vicarious experience, verbal persuasion). Another, possibly complementary, intervention format would be an introductory workshop as part of the CPD course curriculum. In the workshop, tutors could model how to teach and evaluate clinical and non-clinical skills (vicarious experience), then provide participating dentists with an opportunity to practice these skills through role-play (performance), with tutors providing positive feedback and encouragement (verbal persuasion). A workshop format would also enable the dentists to discuss their concerns about training with each other, with further opportunities for the group to suggest ways for each other to overcome these barriers. This seems to be important in regard to becoming a vocational trainer, given anecdotal evidence from the preliminary work informing the development the postal questionnaire. In these consultations we found dentists easily identified barriers to becoming a vocational trainer - time management concerns, perceived personal, professional and financial costs - but found it much more difficult to identify facilitators. The majority of the facilitators appearing in the questionnaire were proposed by the trainer course convenors. It is possible that barriers are more salient when clinicians are requested or expected to perform a behaviour outside everyday practice - which is relevant not just for training a VDP, but also for participating in research or even implementing new clinical guidelines. In future, we may need to develop or emphasise possible facilitators of these 'unusual' behaviours as well as identifying and enabling clinicians to overcome perceived barriers to performing them.

Two concerns need to be taken into account when considering the results of this study. The first is the study design. This was a cross-sectional, predictive study. It is possible that an intervention based on the observed predictive relationship between training self-efficacy and intention to train may still not be targeting a causal agent. Nevertheless, these results do support investigating the effect of manipulating training self-efficacy as a means of increasing the current options for recruiting vocational trainers. The second concern is the representativeness of this sample. One aspect of this is that the response rate was not as high as for many studies. However, the results of the study were generated from participants who were fairly equally split between those who intend to become vocational trainers at some point in time and dentists who intend never to become a vocational trainer. Also, our sample participants came from all over Scotland, with the proportion of dentists from each region in our sample reflecting the proportion per region for all practices in Scotland. Nonetheless, while participants in this study may be representative of dentists practising in Scotland, what is not known is whether dentists practising in Scotland have similar beliefs influencing their decision to become vocational trainers to dentists in the rest of the UK. Further work is needed to investigate this issue.

\section{CONCLUSION}

This study furthered an understanding of what underpins dentists' intention to become a vocational trainer in Scotland. Using a psychological model as a framework for developing the questionnaire provided a means of understanding this decision and a rationale for both the target and the possible formats of interventions to encourage dentists to become vocational trainers. The results suggest that an intervention with the greatest likelihood of success of encouraging dentists to become vocational trainers in Scotland would be one which targets training self-efficacy and which addresses the concerns of both motivated and unmotivated dentists in terms of teaching and evaluative aspects of training, as well as time-management issues. Recruiting vocational trainers is not only a problem for dentistry in Scotland, but throughout the UK. Additionally, general medical practitioners are also needed to oversee medical graduates. The methodology followed in this study could be applied to these issues as well. .

$D B$ led the scientific development, conduct and interpretation of the study; contributed to survey questionnaire development and design; contributed to data analysis; authored drafts of the paper; approved the final version of the paper. JR and SS assisted with the research design and administration of the project and reviewed the manuscript. JC assisted with the scientific development, conduct and interpretation of the study; contributed to survey questionnaire development and design; contributed to data analysis; approved the final version of the paper. The authors wish to acknowledge Kirsteen Doyle, Louise Cardno, Alana Gowans, Kate Levin and NES funding.

1. Bartlett D W, Coward PY, Wilson R, Goodsman D, Darby J. Experiences and perceptions of vocationa training reported by the 1999 cohort of vocationa dental practitioners and their trainers in England and Wales. Br Dent J 2001; 191: 265-270.

2. Baldwin P J, Dodd M, Rennie J S. Postgraduate dental education and the 'new' graduate. Br Dent $J$ 1998; 185: 591-594

3. Prescott LE, McKinlay P, Rennie J S. The development of an assessment system for dental vocational training and general professional training: a Scottish approach. Br Dent J 2001; 190: 41-44.

4. Prescott L E, Norcini J J, McKinlay P, Rennie J S. Facing the challenges of competency-based assessment of postgraduate dental training: longitudinal evaluation of performance (LEP). Med Educ 2002; 36: 92-97.

5. NHS Education for Scotland. Competencies for dental vocational training and general professional training in Scotland. Edinburgh: NHS Education for Scotland, 2002

6. Armitage C J, Conner M. Efficacy of the theory of planned behaviour: a meta-analytic review. Br J Soc Psychol 2001; 40: 471-499.

7. Hardeman W, Johnston M, Johnston D, Bonetti D. Wareham N, Kinmonth A L. Application of the theory of planned behaviour in behaviour change interventions: a systematic review. Psychol Health 2002; 17: 123-158.

8. Walker A E, Grimshaw J M, Armstrong E. Salient beliefs and intentions to prescribe antibiotics for patients with a sore throat. Br J Health Psychol 2001: 6: 347-360.

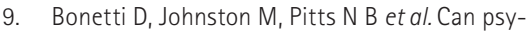
chological models bridge the gap between clinical guidelines and clinicians' behaviour? A randomised controlled trial of an intervention to influence dentists' intention to implement evidence-based practice. Br Dent J 2003; 195: 602-606.

10. Bonetti D, Eccles M, Johnston M et al. Implementation of evidence-based practice: experimental simulation of complex intervention trials. Soc Sci Med 2005; 60: 2135-2147.

11. Bandura A. Self-efficacy - the exercise of control. New York: Freeman \& Company, 1997.

12. Conner M, Norman P (eds). Predicting health behaviour. Research and practice with social cognition models. Buckingham: Open University Press, 1996.

13. Norusis M J/SPSS Inc. SPSS for Windows. Base system user's quide. Release 5.0. Chicago: SPSS Inc. Marketing Department, 1993. 